\title{
Comparative Study of Y-Split Recession versus Faden Technique for Management of Infantile Esotropia in Egyptians
}

\author{
Nermeen Badawi (D) $^{1}$ and Ahmed Taha Ismail (D) $^{2}$ \\ ${ }^{1}$ Ophthalmology Department, Faculty of Medicine, Menoufiya University, Shebin El-Kom, Menoufiya, Egypt \\ ${ }^{2}$ Ophthalmology Department, Faculty of Medicine, Ain-Shams University, Abbaseya, Cairo, Egypt \\ Correspondence should be addressed to Ahmed Taha Ismail; drahmad_taha@yahoo.com
}

Received 7 April 2018; Accepted 12 July 2018; Published 1 August 2018

Academic Editor: Alejandro Cerviño

Copyright (C) 2018 Nermeen Badawi and Ahmed Taha Ismail. This is an open access article distributed under the Creative Commons Attribution License, which permits unrestricted use, distribution, and reproduction in any medium, provided the original work is properly cited.

\begin{abstract}
Purpose. This study compares the results of Y-split recession versus de Decker's (modified Cüppers) Faden techniques of medial rectus (MR) muscles for the management of essential infantile esotropia (IET). Patients and Methods. Fifty patients had IET divided into Group A who underwent Y-split recession of MR muscles and Group B who underwent de Decker's Faden technique of MR muscles. All patients had complete ophthalmic examination done including deviation angle measurement and met the inclusion criteria of the study. Operations were performed using general anesthesia. Patients were followed up at day 1, week 1, and months 1, 3, and 6 after operation. Results. The mean age distribution for group A was 21.56 months (SD 12.55) and for group $\mathrm{B}$ was 21.4 months (SD 12.35), and the mean postoperative follow-up interval was 6 months for both groups. The preoperative maximum angle of deviation in both groups ranged from 15 to 40 degrees, while the minimum angle of deviation ranged from 10 to 20 degrees. Immediately postoperatively both groups showed $88 \%$ of patients with satisfactory results (within 10 degrees of orthotropia). Group A showed two patients (8\%) with ET and one patient (4\%) with exotropia (XT). For group B, it showed one patient (4\%) with ET and two patients (8\%) with XT. Three patients in each group underwent a second intervention. All patients remained within the satisfactory range. Conclusion. The results of this study suggest that both techniques show comparable results for the correction of IET.
\end{abstract}

\section{Introduction}

Infantile esotropia can be managed by minimizing torque ( $T$ ) of medial rectus (MR) muscles. $T=F * r$ [1], where $F$ represents the force exerted by $M R$ and $r$ represents the lever arm. $T$ can be reduced by minimizing $F$ or $r$ [1-6].

Techniques for $r$ reduction include Faden operation, a concept introduced by Cüppers [7-11], which decreases MR $r$ by suturing it to back of the globe. Many studies showed that this controls strabismus [12-14].

Y-split recession mostly involves MR splitting and resuturing thus reducing MR $r$ and effective muscle $F$ [15-19]. It is a concept introduced by Priglinger 1990 and published 1994. Long-term studies and statistical analysis of the outcome after surgical therapy were followed by Haslwanter et al. [18] and Hoerantner et al. [19].

This study aims at comparing both techniques of IET.

\section{Patients and Methods}

The fifty patients involved in this study with big-angle infantile ET were divided into Group A (Y-split recession of $\mathrm{MR}$ ) and Group B (de Decker's Faden technique who, in contrary to Cüppers, preferred to leave the muscle in place and secure it with a triple loop to prevent its sliding through the suture). All patients were subjected to complete ophthalmic examination and met the inclusion criteria, which were (1) ET diagnosed by an ophthalmologist before the age of sixth months, (2) absence of fixation preference, and (3) ET maximum angle values varying from 15 to 40 degrees and were determined using Hirschberg, Krimsky, or prism alternate cover test for distance and near (whenever possible with proper conversion) with optimal refractive correction (whenever needed). Due to variability of strabismus angles, maximum and minimum (static) angles as well as the 
difference between both (dynamic) were measured at each distance three times, and the average was taken for each distance. Exclusion criteria were neurological abnormalities, developmental delays, nystagmus, anomalous head posture (AHP), convergence excess, or ocular structural abnormalities. Cycloplegic refraction was performed, and glasses were used in patients with hyperopia of +3.0 diopter (D) or more for at least one month to exclude any accommodative component. Duction and version movements, oblique muscle overaction, pattern (V or $\mathrm{A})$, and dissociated strabismus were recorded. All operations were performed under general anesthesia using the operating microscope.

Follow-up visits were conducted at 1 day; 1 week; and 1 , 3 , and 6 months postoperatively. Fixation assessment in young children and "illiterate E game" and Snellen acuity chart testing were performed in elderly children for vision assessment. AHP, deviation angle (static and dynamic), convergence, and ocular motility were assessed during follow-up examinations. Rates of reoperation for residual ET or consecutive XT were determined.

Before surgeries, all legal representatives of the patients were told the expected complications. All of them signed informed consents matching Helsinki Declaration.

2.1. Group A: Y-Split Recession Surgical Technique. For the Y-split recession, as described by Priglinger and Hamenter [17], Haslwanter et al. [18], and Hoerantner et al. [19], the surgical parameters were chosen such that $T$ reduction was about 26\%. The surgeon split MR muscles for a length of $15 \mathrm{~mm}$ and sutured the two split-halves to the sclera using nonabsorbable sutures. The two split-halves formed an angle of $62.8 \pm 5.7$ degrees. The muscle was, first, split for a distance of $15 \mathrm{~mm}$, to detect the new accurate insertion for the split-muscle halves, and surgeon performed the following: the first point, labeled "A," was located in the middle of the original insertion. The second point, labeled "B," was located $6 \mathrm{~mm}$ straight behind $\mathrm{A}$. With the compass centered at $\mathrm{A}$, the distance " $r_{\mathrm{A}}$ " was marked on the globe with methylene blue (Figure 1) [19]. Similarly with the compass centered at B, the distance " $r_{\mathrm{B}}$ " was marked on the globe. The crossing points of the methylene blue lines locate the new insertion of the split-muscle halves. Both muscle halves were secured using $5 / 0$ polyester suture with a spatulated needle (Ethicon ${ }^{\circledR}$ ).

2.2. Group B: de Decker's Faden Technique. All children received a simple retroequatorial strapping of both $M R$ $14 \mathrm{~mm}$ posteriorly from their scleral insertion with a nonabsorbable $5 / 0$ polyester suture with a spatulated needle (Ethicon). This was performed after careful dissection of connective tissues around the muscle body as far as the site of suturing the muscle. Two sutures were used at the muscle edge. The sutures were simply fixed to the sclera on both sides of the muscle fixing its margins in a triple loop fashion to prevent its sliding through the suture (Figure 2).

No orthoptic exercises were performed after surgery. Patients continued to wear glasses (if needed) and were watched regularly for alignment and change of refraction. Statistical analysis was done using mean analysis, correlation t-tests, Mann-Whitney test, and Friedman test. A $P$ value lower than 0.05 was considered statistically significant.

\section{Results}

The age distribution for Group A (Y-split recession) ranged from 9 to 54 months, with a mean of 21.56 months (SD 12.55) and for Group B (de Decker's Faden technique) ranged from 8 to 48 months, with a mean of 21.4 months (SD 12.35). There was a statistically nonsignificant difference in age distribution between both groups by the Mann-Whitney test. This is shown by patients' distribution by age (Figure 3 ).

The mean postoperative follow-up interval was 6 months for both groups. The mean surgical time for Group A (Ysplit recession) was 50 minutes (SD 13.50) and for Group B de Decker's Faden technique was 40 minutes (SD 10.05) that means that Group A consuming more operative time by $20 \%$ than Group B. It should be noted that the technique of $\mathrm{Y}$-split recession included more steps and necessitated that the limbal incision has to be steeper up to the intended refixation points and $\mathrm{MR}$ has to be split about $15 \mathrm{~mm}$ from insertion. Yet, the surgical area was more anterior and hence safer. No patient developed nystagmus, AHP, or convergence excess. The average values of the maximum, minimum (static), and dynamic strabismus angles preoperatively, one day; one week; and one, three, and six months postoperatively are shown in (Tables 1-3).

The mean postoperative follow-up interval was 6 months for both groups. Criteria of patients satisfaction were postulated as (i) satisfactory surgical outcome within 10 degrees of orthotropia and (ii) unsatisfactory surgical outcome if ET or XT $\geq 10$ degrees. Both groups showed a statistically highly significant reduction in postoperative maximum, minimum (static), and dynamic strabismus angles compared to preoperative ones in every postoperative follow-up visit by the Friedman test $(P<0.001)$. However, both groups showed a statistically nonsignificant difference in postoperative maximum and minimum strabismus angles in every postoperative follow-up visit by the Mann-Whitney test (Figures 4 and 5).

Immediately postoperatively both groups showed $80 \%$ satisfactory results. As for the unsatisfactory results, Group A showed 4 cases (16\%) with minimum residual ET angle $\geq 10$ degrees and one case (4\%) with minimum consecutive XT angle $\geq 10$ degrees, while those of Group B showed one cases (4\%) with minimum residual ET angle $\geq 10$ degrees and 4 cases (16\%) with minimum consecutive XT angle $\geq 10$ degrees.

By the end of the first postoperative month, 2 cases of Group A (8\%) with the minimum residual ET angle improved to the satisfactory range, increasing the number of satisfactory cases to be $88 \%$. On the contrary, 2 cases of Group B (8\%) one with minimum residual ET angle and another one with minimum consecutive XT angle improved to the satisfactory range, increasing the number of satisfactory cases to be $88 \%$.

Patients whose results were unsatisfactory underwent a second intervention by the end of the postoperative second month. Intervention was in the form of lateral rectus (LR) 


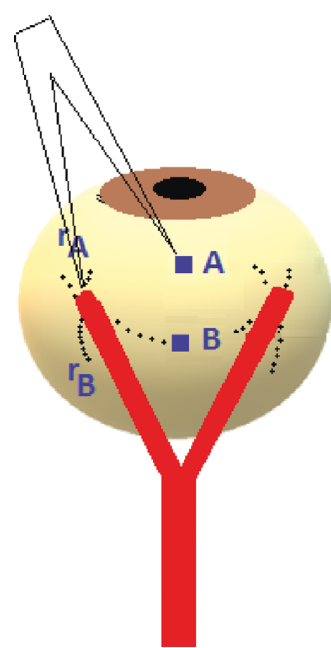

(a)

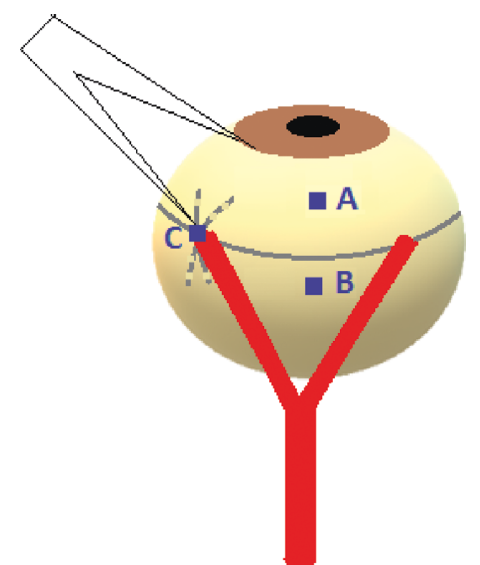

(b)

FIGURE 1: A sketch of Y-split recession, side view. (a) The first orientation point ("A") is given by the middle of the natural muscle insertion. The second orientation point ("B") is located $6 \mathrm{~mm}$ straight behind A. With a compass, the distance $r_{\mathrm{A}}$ is marked with color on the globe. The same procedure is repeated from $\mathrm{B}$, with the distance $r_{\mathrm{B}}$. The intersection of the two marked lines indicates the new insertion points for the split-muscle halves. (b) The "control distance" ("C") ensures correct placement of the new insertion points.

resection in patients with residual ET and LR recession in patients with consecutive XT. All patients remained within the satisfactory range during the rest of follow-up period.

\section{Discussion}

Variable angle strabismus, like IET, can be treated by different methods. Simple recession of the concerned muscles would correct minimal strabismus angle through reducing muscle $F$ only [19]. However, strabismus angle variability remains unchanged. A better way to correct the variable angle strabismus is through reduction of extraocular muscles $r$ as well. Two surgical techniques can be used including Faden technique and Y-split recession. Priglinger and Hamenter [17], Haslwanter et al. [18], and Hoerantner et al. [19] have previously shown that the biomechanics underlying these techniques are quite different. In Faden technique, the muscle is sutured to the posterior half of the globe (which is not without complications in high myopic and aphakic eyes) [17-19]. This will change the arc of contact of the muscle with the globe reducing $r$ [12]. It would also make the $F$ exerted by muscle contraction split into a radial $F$ component (pulling at the suture) and a tangential $F$ component (rotating the eye). In higher globe excursions, $F$ becomes radial leading to blocked ocular motility [18]. With Y-split recession, the muscle is split along $15 \mathrm{~mm}$, and both split-halves are reattached, as shown in Figure 1. Thus, $r$ of the muscle is reduced as both halves slide to the side, without any pull in the radial direction due to absence of posterior attachment $[1,20,21]$. It also reduces $F$ due to associating recession [19]. It also reduces the difference between larger near deviation and distance deviation with stable long-term effects [22, 23]. Unlike the Faden technique, the $T$ reduction with $\mathrm{Y}$-split recession is approximately constant throughout the oculomotor range resulting in less incomitance than that with Faden technique [17-19].

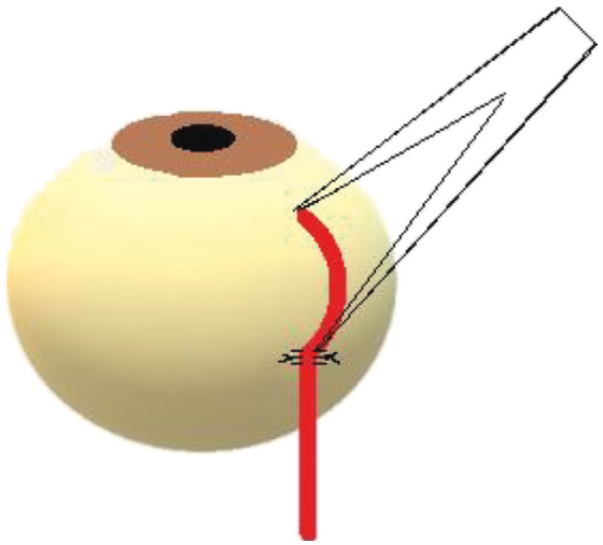

Figure 2: A sketch of de Decker's Faden technique, side view.

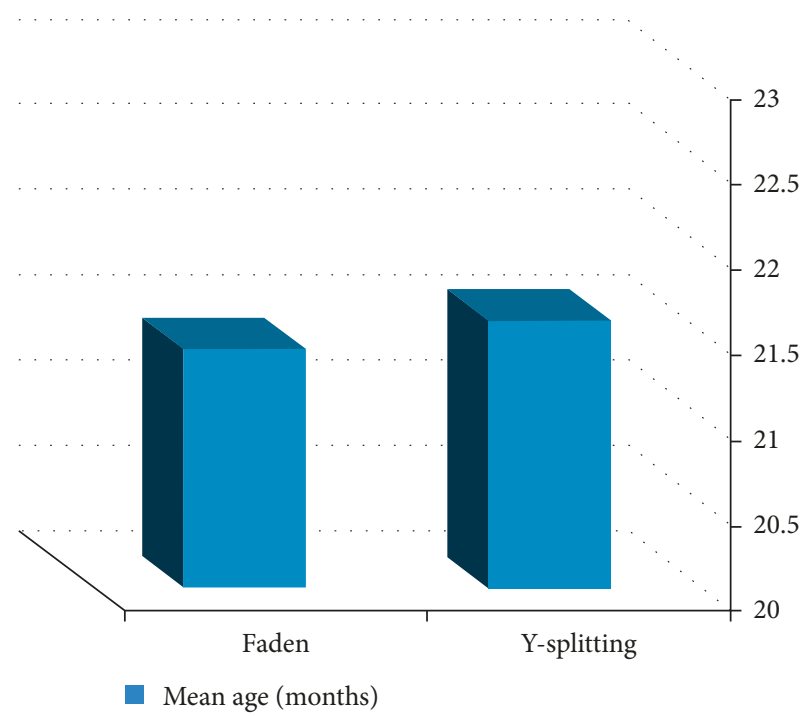

FIgUre 3: Patients' profile showing patients' distribution by age. 
TABle 1: The average values of the maximum strabismus angles preoperatively, one day; one week; one, three, and six months postoperatively.

\begin{tabular}{|c|c|c|c|c|c|c|}
\hline & \multicolumn{6}{|c|}{ Maximum strabismus angle (degrees $\pm \mathrm{SD}$ ) } \\
\hline & Preoperative & $\begin{array}{c}1 \text {-day } \\
\text { postoperative }\end{array}$ & $\begin{array}{c}1 \text {-week } \\
\text { postoperative }\end{array}$ & $\begin{array}{c}1 \text {-month } \\
\text { postoperative }\end{array}$ & $\begin{array}{c}\text { 3-month } \\
\text { postoperative }\end{array}$ & $\begin{array}{c}\text { 6-month } \\
\text { postoperative }\end{array}$ \\
\hline \multirow{2}{*}{ Y-splitting } & \multirow{2}{*}{$25.8 \pm 8.124$} & $1.6 \pm 6.4096$ & $1.2 \pm 6.1712$ & $1.2 \pm 6.1712$ & 0 & 0 \\
\hline & & $P<0.001$ & $P<0.001$ & $P<0.001$ & $P<0.001$ & $P<0.001$ \\
\hline \multirow[t]{2}{*}{ Faden } & \multirow[t]{2}{*}{$26.6 \pm 7.0297$} & $-0.6 \pm 6.69$ & $-1 \pm 5.5902$ & $-1 \pm 5.5902$ & 0 & 0 \\
\hline & & $P<0.001$ & $P<0.001$ & $P<0.001$ & $P<0.001$ & $P<0.001$ \\
\hline
\end{tabular}

TABLE 2: The average values of the minimum strabismus angles preoperatively, one day; one week; one, three, and six months postoperatively.

\begin{tabular}{lcccccc}
\hline & \multicolumn{4}{c}{ Minimum (static) strabismus angle (degrees \pm SD) } \\
& Preoperative & 1-day & 1-week & 1-month & 3-month & 6-month \\
& & postoperative & postoperative & postoperative & postoperative & postoperative \\
& \multirow{2}{*}{$12 \pm 3.2275$} & $1 \pm 5$ & $0.6 \pm 4.6368$ & $0.2 \pm 4.2032$ & 0 & 0 \\
Y-splitting & & $P<0.001$ & $P<0.001$ & $P<0.001$ & $P<0.001$ & 0 \\
Faden & $13 \pm 3.5355$ & $-0.4 \pm 4.5461$ & $-0.8 \pm 4$ & $-0.4 \pm 3.5119$ & 0.001 & 0 \\
& & $P<0.001$ & $P<0.001$ & $P<0.001$ & $P<0.001$ & $P<0.001$ \\
\hline
\end{tabular}

TABLE 3: The average values of the dynamic strabismus angles preoperatively, one day; one week; one, three, and six months postoperatively.

\begin{tabular}{lcccccc}
\hline & \multicolumn{3}{c}{ Dynamic strabismus angle (degrees \pm SD) } \\
& Preoperative & $\begin{array}{c}\text { 1-day } \\
\text { postoperative }\end{array}$ & $\begin{array}{c}\text { 1-week } \\
\text { postoperative }\end{array}$ & $\begin{array}{c}\text { 1-month } \\
\text { postoperative }\end{array}$ & $\begin{array}{c}\text { 3-month } \\
\text { postoperative }\end{array}$ 6-month \\
postoperative
\end{tabular}

This study is, as far reviewed in the literature, the first study comparing these 2 techniques in this category of patients.

Hoerantner et al. [19] reported that around $1 \%$ of the all patients who have undergone $\mathrm{Y}$-split recession have been reoperated a few months later. This was different from the current study which showed that $12 \%$ of patients with Y-split recession underwent a second operation. The difference could be attributed to the difference in the number of patients (228 versus 50 patients in the current study). The split muscle was found with no scar tissue between globe and muscle, and the muscle was situated as it was immediately after Y-split surgery. The surface of the muscle halves was covered by a smooth, white tissue unattached to any surrounding structure.

In the current study, the larger $T$ reduction achieved with the de Decker's Faden technique in adduction showed no advantage over Y-split recession which showed equal results to those of the de Decker's Faden technique.

In a study performed by Hoerantner et al. [24], they indicated that $\mathrm{Y}$-split recession represents a powerful alternative to Faden technique. During follow-up visit three months postoperatively, patients with Y-split recession showed a significantly more decreases in maximum strabismus angle. They attributed these improved results to

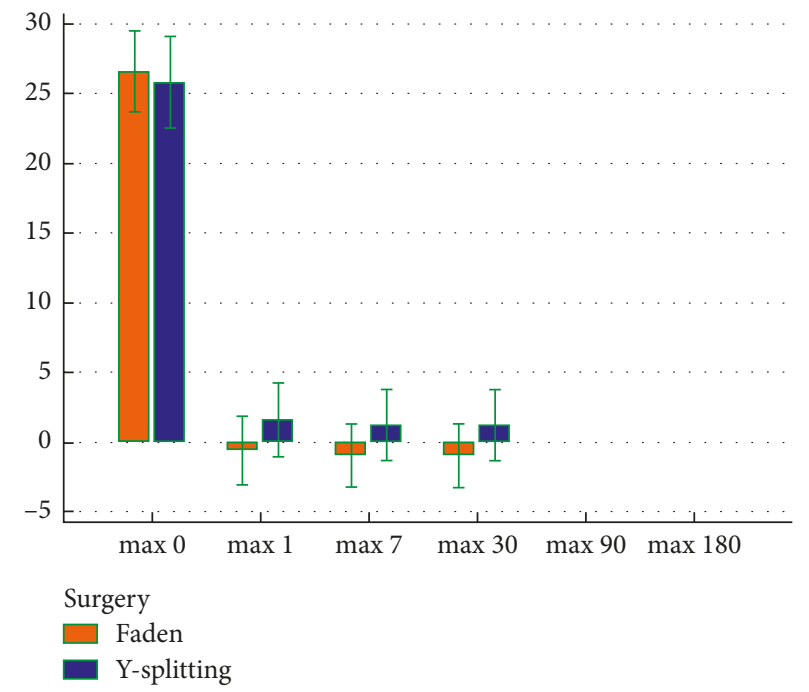

FIgURE 4: Preoperative and postoperative maximum strabismus angles in both groups.

surgical advantages of this technique which reduces $r$ and also $F$ (through recession) in one operative step, which allows for greater flexibility in the choice of the surgical parameters. However, the recession is influenced by reduced 


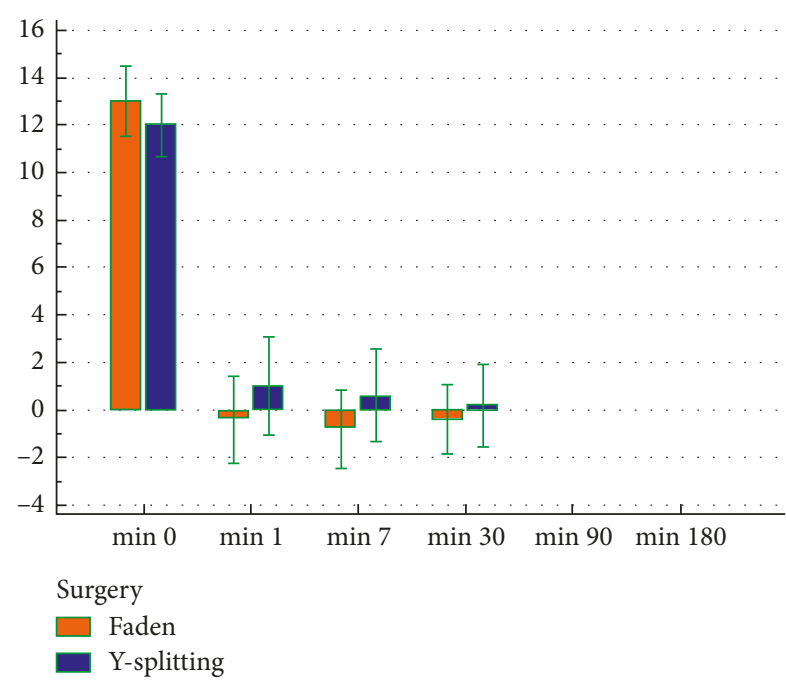

Figure 5: Preoperative and postoperative minimum strabismus angles in both groups.

$r$ of the operated muscle; therefore, the calculation of the muscle recession at a shorter $r$ needs a smaller dose-effect relationship. The postoperative angle reduction within days, respective over longer time, may change by a feedback mechanism and adaptation effect. This was in contrast to the current study which showed similar success rate in both groups. This could be attributed to different Faden technique (Cüppers versus de Decker's in the current study) and different numbers of patients (100 versus 50 patients in the current study). They showed that the surgical area in Y-split recession is anterior to that in the Faden technique and is therefore easier to access, safer, and more accurate [17-19].

In the current study, both techniques showed a significant reduction in both static and dynamic strabismus angles. This was similar to the results obtained by Hoerantner et al. [19] and Hoerantner et al. [24].

\section{Conclusion}

This study shows that both Y-split recession and de Decker's Faden techniques are efficient procedures in $88 \%$ of infantile ET. Long-term follow-up will tell if these results are stable with time and if there will be a reduction in the rate of recurring surgery.

\section{Data Availability}

The data used to support the findings of this study are available from the corresponding author upon request.

\section{Conflicts of Interest}

The authors declare that they have no conflicts of interest.

\section{Acknowledgments}

The authors are very thankful to Dr. Maged Maher for his sincere help.

\section{References}

[1] R. J. Leitch, J. P. Burke, and I. M. Strachan, "Convergence excess esotropia treated surgically with Faden operation and medical rectus muscle recessions," British Journal of Ophthalmology, vol. 74, no. 5, pp. 278-279, 1990.

[2] D. R. Stager, D. R. Weakley Jr., and M. Everett, "Delayed consecutive exotropia following $7-\mathrm{mm}$ bilateral medial rectus recession for congenital esotropia," Journal of Pediatric Ophthalmology and Strabismus, vol. 31, pp. 147-150, 1994.

[3] E. E. Birch, J. Felius, D. R. Stager Sr., D. R. Weakley Jr., and R. G. Bosworth, "Preoperative stability of infantile esotropia and post-operative outcome," American Journal of Ophthalmology, vol. 138, no. 6, pp. 1003-1009, 2004.

[4] M. F. Ruiz, M. T. Alvarez, C. M. Sanchez-Garrido, J. M. Hernaez, and J. M. Rodriguez, "Surgery and botulinum toxin in congenital esotropia," Canadian Journal of Ophthalmology, vol. 39, no. 6, pp. 639-649, 2004.

[5] S. Elliott and A. Shafiq, "Interventions for infantile esotropia," Cochrane Database Systematic Review, vol. 7, article CD004917, 2013.

[6] C. Hemmerdinger, N. Rowe, L. Baker, and I. C. Lloyd, "Bimedial hang-back recession-outcomes and surgical response," Eye, vol. 19, no. 11, pp. 1178-1181, 2005.

[7] C. Cüppers, "Moderne schielbehandlung," Klin Monatsbl Augenheilkd, vol. 129, pp. 579-604, 1956.

[8] C. Cüppers, "Grenzen und möglichkeiten der pleoptischen therapie," Klin Monatsbl Augenheilkd, vol. 381, p. 33, 1961.

[9] C. Cüppers, "Some reflections on the possibility of influencing the pathological fixation act," Annals of the Royal College of Surgeons of England, vol. 38, pp. 308-325, 1966.

[10] E. de Decker and W. de Decker, "Improved fixation of unilateral suture operation of the rectus medialis muscle of the amblyopic eye," Klin Monatsbl Augenheilkd, vol. 212, no. 4, pp. 203-206, 1998.

[11] H. Steffen, G. U. Auffarth, and G. H. Kolling, "Posterior fixation suture and convergence excess esotropia," Strabismus, vol. 6, no. 3, pp. 117-126, 1998.

[12] A. B. Scott, "The Faden operation: mechanical effects," American Orthoptic Journal, vol. 27, no. 1, pp. 44-47, 1977.

[13] E. M. Helveston, Surgical Management of Strabismus: An Atlas of Strabismus Surgery, Mosby, St. Louis, MI, USA, 4th edition, 1993

[14] R. A. Clark, S. J. Isenberg, A. L. Rosenbaum, and J. L. Demer, "Posterior fixation sutures: a revised mechanical explanation for the Faden operation based on rectus extraocular muscle pulleys," American Journal of Ophthalmology, vol. 128, no. 6, pp. 702-714, 1999.

[15] A. M. Castanera, "Length/tension diagrams of medial rectus muscles after Cüppers' Faden operation. Surgical assessment of the reversibility of posterior fixation sutures," Ophthalmologica, vol. 198, no. 1, pp. 46-52, 1989.

[16] P. Roggenkamper, "The Faden operation. Technical aspects and indications," Bulletin de la Société Belge d'Ophtalmologie, vol. 232, pp. 25-31, 1989.

[17] S. Priglinger and H. Hametner, "Operative methoden zur behandlung des schwankenden schielwinkels. Mathematische zusammenhänge-computergestützte operation splanung," Spektrum der Augenheilkunde, vol. 8, no. 4, pp. 162-175, 1994.

[18] T. Haslwanter, R. Hoerantner, and S. Priglinger, "Reduction of ocular muscle power by splitting of the rectus muscle. I: biomechanics," British Journal of Ophthalmology, vol. 88, no. 11, pp. 1403-1408, 2004. 
[19] R. Hoerantner, S. Priglinger, and T. Haslwanter, "Reduction of ocular muscle torque by splitting of the rectus muscle II: technique and results," British Journal of Ophthalmology, vol. 88, no. 11, pp. 1409-1413, 2004.

[20] R. A. Clark and J. L. Demer, "Rectus extraocular muscle pulley displacement after surgical transposition and posterior fixation for treatment of paralytic strabismus," American Journal of Ophthalmology, vol. 133, no. 1, pp. 119-128, 2002.

[21] N. Badawi and K. Hegazy, "Comparative study of Y-split recession versus bilateral medial rectus recession for surgical management of infantile esotropia," Clinical Ophthalmology, vol. 8, pp. 1039-1045, 2014.

[22] O. Ehrt, "Conservative and surgical treatment of convergence excess," Der Ophthalmologe, vol. 113, no. 7, pp. 550-556, 2016.

[23] M. Wipf, S. Priglimger, and A. Palmowske-Wolfe, "Y-split recession of the medial rectus muscle as a secondary and/or unilateral procedure in the treatment of esotropia with distance/near disparity," Journal of Ophthalmology, vol. 2017, Article ID 6472690, 6 pages, 2017.

[24] R. Hoerantner, S. Priglinger, M. Koch, and T. Haslwanter, "A comparison of two different techniques for oculomotor torque reduction," Acta Ophthalmologica Scandinavica, vol. 85, no. 7, pp. 734-738, 2007. 


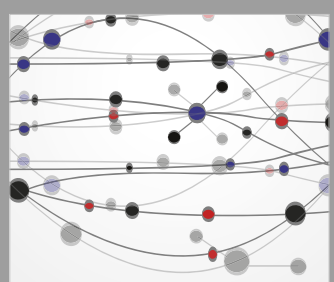

The Scientific World Journal
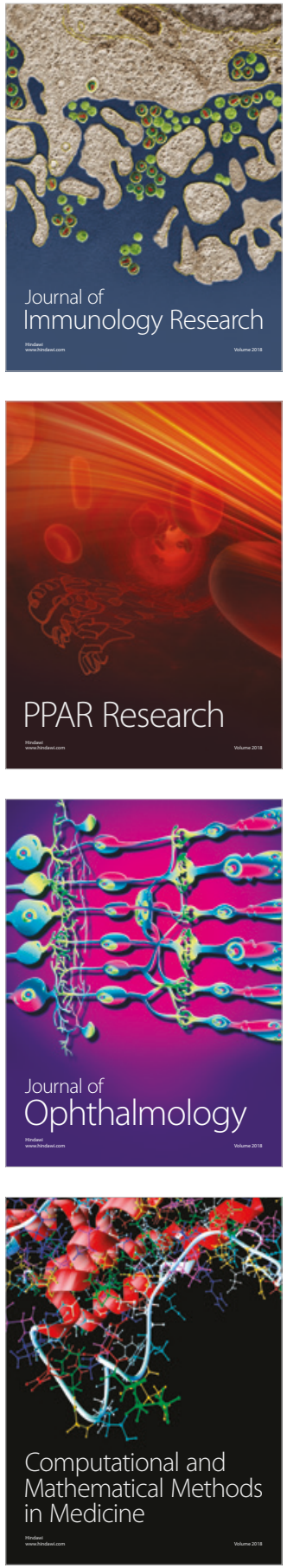

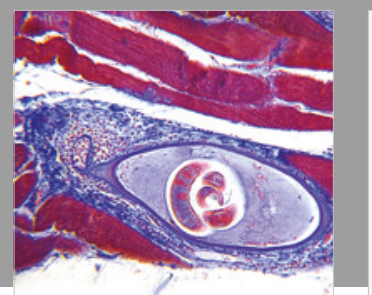

Gastroenterology Research and Practice

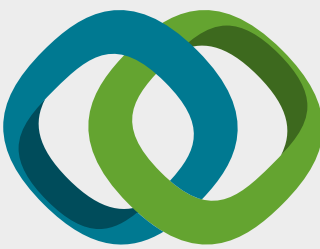

\section{Hindawi}

Submit your manuscripts at

www.hindawi.com
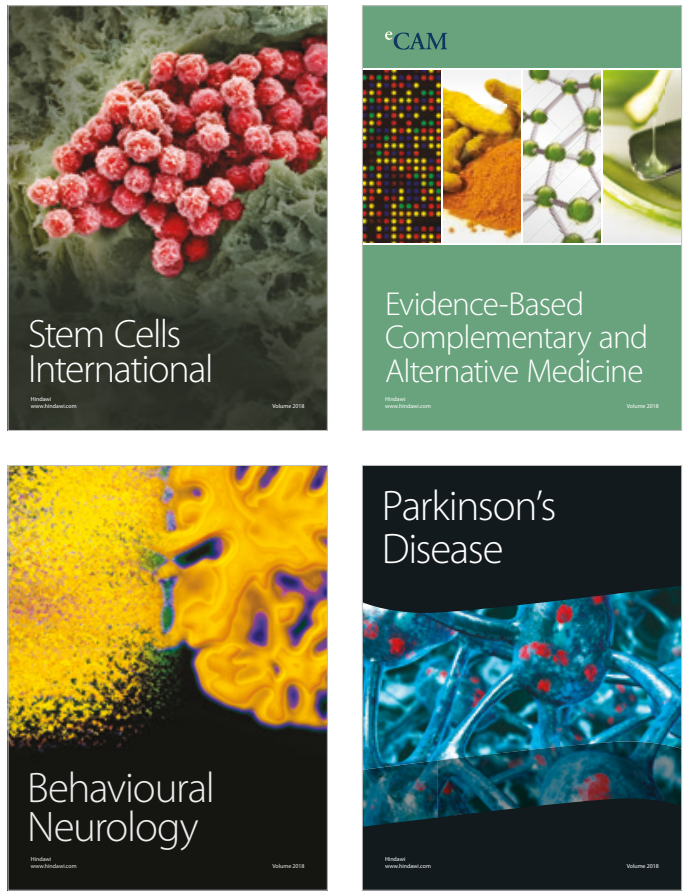

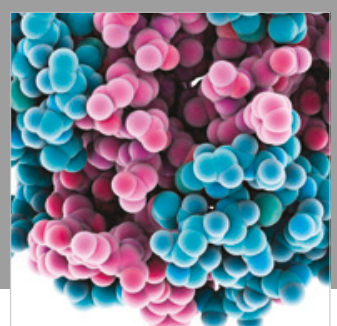

ournal of

Diabetes Research

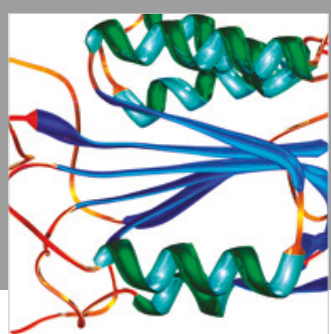

Disease Markers
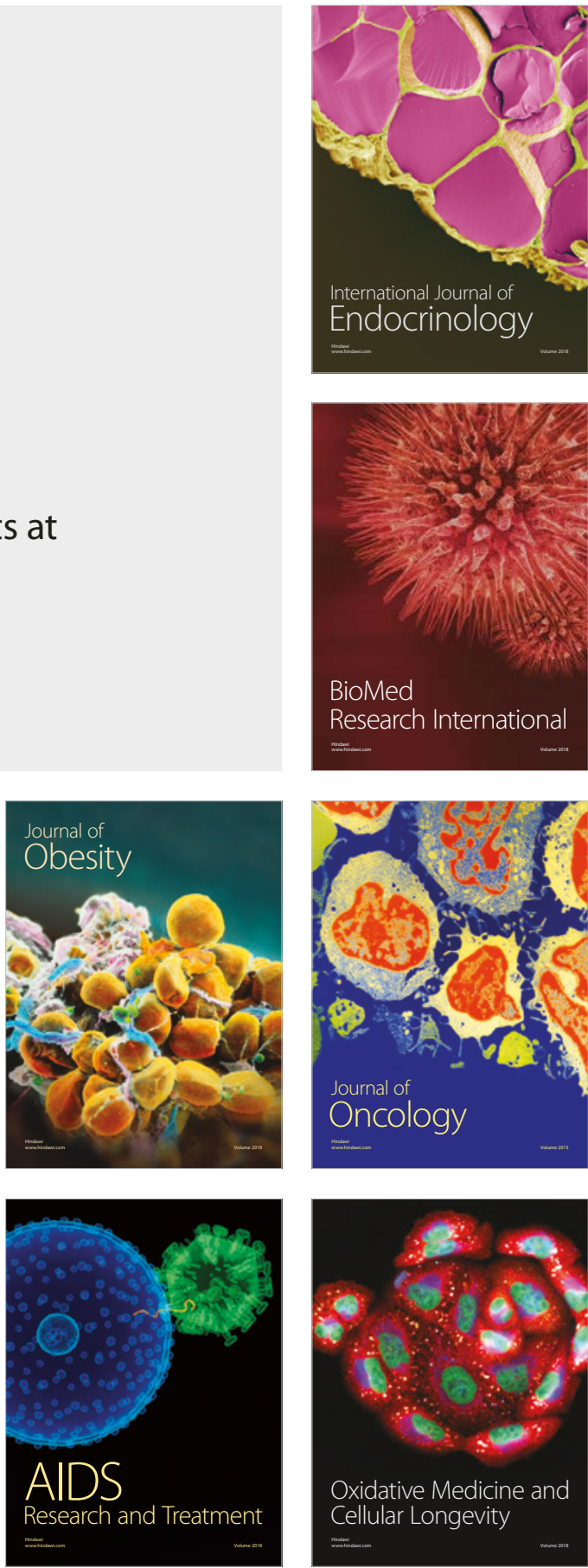